\title{
GENOTYPE BY ENVIRONMENT INTERACTION FOR GRAIN YIELD OF BARLEY MUTANT LINES
}

\author{
BORYANA DYULGEROVA*, NIKOLAY DYULGEROV
}

Institute of Agriculture-Karnobat, Bulgaria

DYUlgerova, B. - DYUlGerov, N.: Genotype by environment interaction for grain yield of barley mutant lines. Agriculture (Polnohospodárstvo), vol. 65, 2019, no. 2, pp. $51-58$.

\begin{abstract}
The aim of this study was to examine the genotype by environment interaction for grain yield and to identify high-yielding and stable mutant lines of 6-rowed winter barley under different growing seasons. The study was carried out during 7 growing seasons from 2010-2011 to 2016-2017 in the experimental field of the Institute of Agriculture - Karnobat, Southeastern Bulgaria. Fourteen advanced mutant lines and the check variety Vesletc were studied using a complete block design with 4 replications. The AMMI analysis of variance indicated that $20.54 \%$ of the variation for grain yield was explained by the effect of genotype and $37.34 \%$ and $42.12 \%$ were attributable to the environmental effects and genotype by environment interaction. The magnitude of the genotype by environment interaction was two times larger than that of genotypes, indicating that there was a substantial difference in genotype response across environments. The AMMI and GGE biplot analyses identified G9 as the highest yielding and stable genotype. This mutant line can be recommended for further evaluation for variety release. The mutant lines G6, G13 and G15 were suggested for inclusion in the breeding program of winter barley due to its high grain yield and intermediate stability.
\end{abstract}

Key words: AMMI analysis, barley, GGE analysis, mutant, stability, yield

Barley (Hordeum vulgare L.) is one of the important cereals in Bulgaria, mainly used for animal feed and malt. Barley breeding is aimed at the development of new varieties with high yield potential and improved response to agronomic inputs (Friedt 2011; Mihova 2013; Valcheva et al. 2013; Gocheva 2014; Pržulj et al. 2014). Many breeding techniques are being used successfully in barley to improve grain yield and other agronomically important traits. Mutation breeding is one of the important techniques to induce genetic variation in barley and more than 300 barley varieties have been officially released by mutation breeding (Joint FAO/IAEA Mutant Variety Database 2019).

Mutation breeding is part of the winter barley breeding program at the Institute of Agriculture - Kar- nobat and has led to the development of new barley varieties with high and stable grain yield as IZ Bori, Bojin, Zemela and Ahil.

Barley varieties react differently to a number of factors such as moisture stress, high and low temperatures, soil fertility, disease pressure and different agronomic practices, expressing a yield ranking change across environments, termed Genotype by environment interaction (GEI). GEI reduces genetic progress in breeding programs by minimizing associations between phenotypes and genotypes and complicates testing and selection of superior genotypes (Voltas et al. 2002).

There are many methods for GEI analysis, which all aim at the identification of genotypes suitable for certain growing regions. Interactions are usually ex-

Assoc. Prof. Boryana Dyulgerova, PhD. (*Corresponding author), Institute of Agriculture - Karnobat 1, Industialna Str., 8400 Karnobat, Bulgaria. E-mail: bdyulgerova@abv.bg

Senior Assistant Nikolay Dyulgerov, PhD., Institute of Agriculture - Karnobat 1, Industialna Str., 8400 Karnobat, Bulgaria. E-mail: nikolaydyulgerov@gmail.com 
plained in more complex methods based on analysis of variance, regression analysis, principal component analysis (PCA), cluster analysis and other methods of multivariate analysis such as AMMI model (Additive Main Effects and Multiplicative Interaction, Gauch \& Zobel 1996) and GGE biplot analysis (Genotype and Genotype by Environment interaction, Yan et al. 2000).

The Additive Main effect and Multiplicative Interaction (AMMI) method proposed by Gauch (1992) was a significant advance in the analysis and interpretation of GEI. This method is a combination of ANOVA for the main effects of the genotypes and environments together with a principal component analysis of the genotype by environment interaction which leads to identification of stable genotypes as well as to widely or specifically adapted genotypes (Gauch 1988; Zobel et al. 1988).

Yan et al. (2000) proposed another methodology known as GGE biplot for graphical display of GE interaction pattern with many advantages. The GGE biplot analysis considers both genotype (G) and GE interaction effects and graphically displays the GE interaction in a two way table (Yan et al. 2000). GGE biplot is an effective method based on principal component analysis (PCA). This is done using singular value decomposition to break the data matrix into component matrices. The first two principal components (PC1 and PC2) are used to produce a two-dimensional GGE biplot. If a large portion of the variation is explained by these components, a rank-two matrix, represented by a GGE biplot, is appropriate (Yan \& Kang 2003). Using a mixed model analysis may offer superior results when the regression of genotype by environment interaction on environment effect does not explain all the interaction (Yan \& Rajcan 2002).

The aim of this study was to examine the genotype by environment interaction for grain yield and to identify high-yielding and stable mutant lines of 6-rowed winter barley under different growing seasons in Southeast Bulgaria, using AMMI and GGE biplot methods.

\section{MATERIAL AND METHODS}

This study was carried out during 7 growing seasons - from 2010-2011 to 2016-2017 (E1 -
2010-2011; E2 - 2011-2012; E3 - 2012-2013; E4 - 2013-2014; E5 - 2014-2015; E6 - 20152016; E7 - 2016-2017) in the experimental field of the Institute of Agriculture - Karnobat, Southeastern Bulgaria.

The experimental area has a transitional continental climate, with long and relatively cool spring, dry and hot summer, long and rainy autumn, and little snow in winter, with large variations of temperatures. Monthly average temperature and precipitation during the experimental period are shown in Figure 1 and 2. The soil of the experimental field is leached vertisol, slightly acid ( $\mathrm{pH}$ is 6.2).

The experiments were organized in a complete block design with 4 replications on plots of $10 \mathrm{~m}^{2}$. The plot yield was converted to t/ha. Standard agronomic and plant protection practices were used.

Fourteen advanced mutant lines (from G2 to G15) of 6-rowed winter barley of mutation breeding program of the Institute of Agriculture - Karnobat were studied along with check variety Vesletc (G1) - national standard variety. Mutant lines were developed after treatment of pre-soaked for $16 \mathrm{~h}$ seed with $2 \mathrm{mM}$ sodium azide for 2 hours and continuous selection for grain yield in M2 and subsequent mutant generations.

Data of grain yield $[\mathrm{t} / \mathrm{ha}$ ] from the multi-year trial was subjected to Duncan multiple range test to explain the significant differences among means of genotypes and to an analysis of genotypic stability using AMMI and GGE biplot approaches.

AMMI model was used to distinguish the genotype main effect, environment main effect and GEI. The AMMI model equation was:

$$
\mathrm{Y}_{i j}=\mu+g_{i}+e_{j}+\sum_{1}^{N} \lambda_{\mathrm{k}} \mathrm{Y}_{i k} \delta_{j k}+\rho_{i j}+\varepsilon_{i j}
$$

where: $\mathrm{Y}_{i j}$ was the grain yield of the $i$-th genotype in the $j$-th environment; $\mu$ was the grand mean; $g_{i}$ and $e_{j}$ were the genotype and environment deviation from the grand mean, respectively; $\lambda_{k}$ was the eigenvalue of the PCA axis k; $\mathrm{Y}_{i k}$ and $\delta_{j k}$ were the genotype and environment principal component scores for axis k; $N$ was the number of principal components retained in the model, $\rho_{i j}$ was residual and $\varepsilon_{i j}$ was the residual term.

AMMI stability value (ASV) was calculated in the excel spreadsheet using the formula developed by Purchase et al. (2000): 


$$
A S V=\sqrt{\left[\frac{I P S A 1_{S Q}}{\left[P S A 2_{S Q}\right.}\left(I P S A 1_{\text {score }}\right)\right]+\left(I P S A 2_{\text {score }}\right)^{2}}
$$

where: SQ - sum of squares; IPCA1 - interaction of principal component analysis one; IPCA2 - interaction of principal component analysis two.

Yield stability index (YSI) was computed by summing up the ranks from ASV and mean grain yield (Farshadfar et al. 2008):

$$
\mathrm{YSI}=\mathrm{RASV}+\mathrm{RGY}
$$

where: RASV is the rank of AMMI stability value and RGY is rank of mean grain yield.

Statistical analyses were performed using the GenStat $12^{\text {th }}$ edition (GenStat 2009). GGE biplot methodology, which is composed of 2 concepts, the biplot concept (Gabriel 1971) and the GGE concept (Yan et al. 2000) was used to visually analyse the data. This methodology uses a biplot to show the factors ( $\mathrm{G}$ and $\mathrm{GEI})$ that are important in genotype

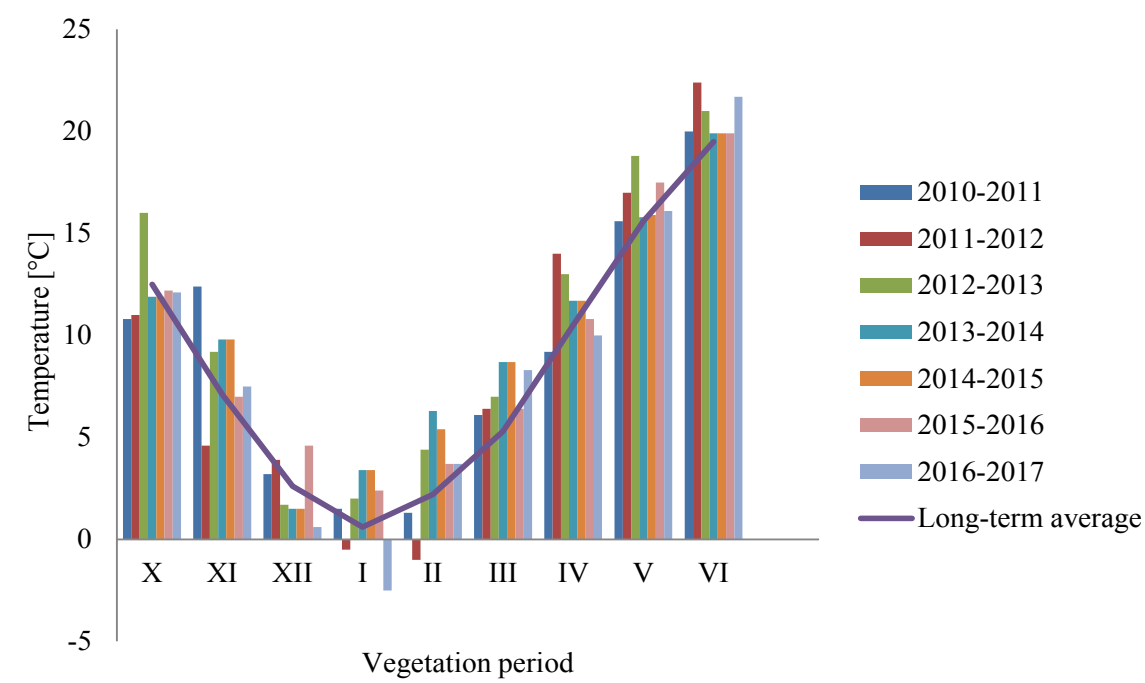

Figure 1. Temperature $\left[{ }^{\circ} \mathrm{C}\right]$ from $2010-2011$ to $2016-2017$ growing seasons and long-term average (1931-2017) at the experimental side of the Institute of Agriculture - Karnobat

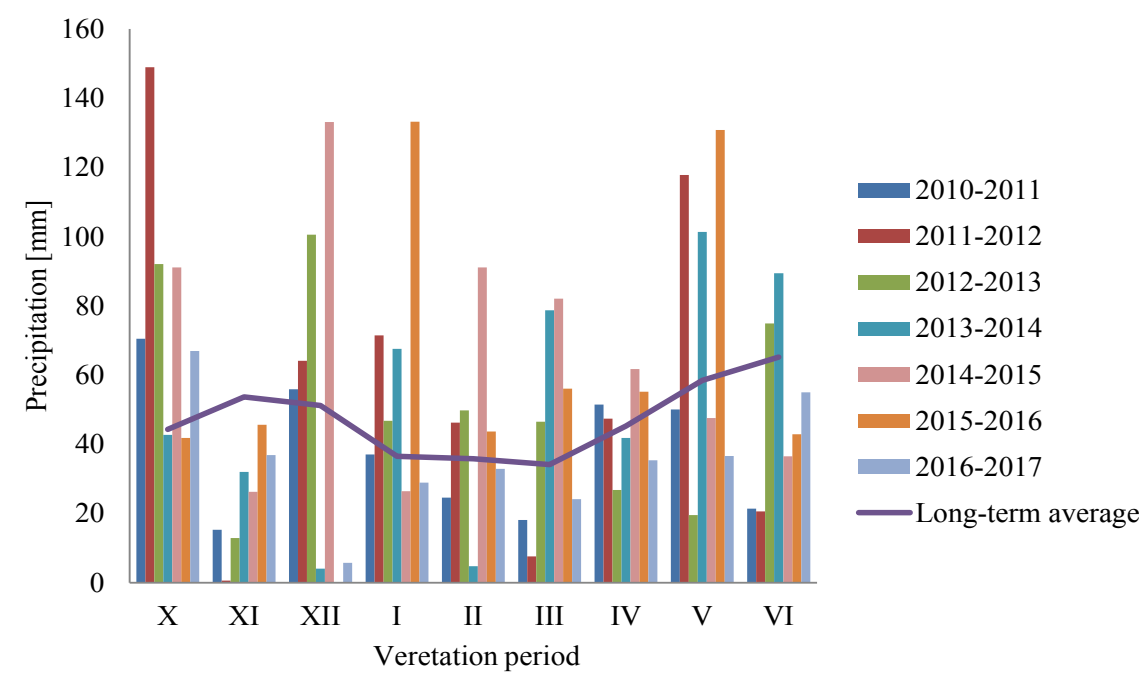

Figure 2. Precipitation [mm] from 2010-2011 to 2016-2017 growing seasons and long-term average (1931-2017) at the experimental side of the Institute of Agriculture - Karnobat 
evaluation and that are also the source of variation in the GEI analysis of METs data (Yan et al. 2000). The GGE-biplot shows the first 2 principal components (PC1 and PC2) derived from subjecting environment-centered yield data (yield variation due to GGE) to singular value decomposition (Yan et al. 2000). In the current study, genotype-focused scaling was used in visualizing for genotypic comparison, with environment-focused scaling for environmental comparison.

\section{RESULTS AND DISCUSSION}

The mean grain yield of the studied mutant lines and check variety during 2010-2011 - 2016-2017 growing years are presented in Table 1. Overall mean grain yield over 7 years was $6.50 \mathrm{t} / \mathrm{ha}$ and the mean grain yield across years ranged between $5.53 \mathrm{t} / \mathrm{ha}$ in $2016-2017$ to $7.04 \mathrm{t} /$ ha $2012-2013$.
The highest grain yield $-8.76 \mathrm{t} /$ ha was found in G9 (2010-2011) and lowest - 4.78 t/ha in G14 (20162017). G9 had the highest mean grain yield $7.29 \mathrm{t} / \mathrm{ha}$ followed by G6 (6.92 t/ha), G15 (6.90 t/ha) and G13 $(6.89 \mathrm{t} / \mathrm{ha})$. Most of the studied mutant lines (G3, G4, G5, G6, G9, G10, G11, G12, G13, G14 and G15) had significantly higher mean grain yield than the standard variety. Moreover, genotypes G9, G6, G15, and G13 showed $17.51 \%, 11.55 \%, 11.11 \%$ and $10.95 \%$ yield advantage over the standard variety.

The results of AMMI analysis showed that grain yield was significantly affected by genotype, environment and GEI (Table 2). The AMMI analysis of variance indicated that $20.54 \%$ of the total sum of squares (SS) for grain yield was explained by the effect of genotype (G) and $37.34 \%$ and $42.12 \%$ of the total SS were attributable to the environment (E) effects and GEI. The magnitude of the GEI sum of squares was two times larger than that of genotypes, indicating that there was a substantial difference in

$\mathrm{T}$ a $\mathrm{b} 1$ e 1

Mean grain yield [t/ha] of of barley genotypes in seven growing seasons $(2010-2011-2016-2017)$

\begin{tabular}{|l|l|l|l|l|l|l|l|l|}
\hline Genotype & E1 & E2 & E3 & E4 & E5 & E6 & E7 & Mean \\
\hline G1 & $6.43^{\mathrm{ef}}$ & $5.66^{\mathrm{i}}$ & $6.48^{\mathrm{e}}$ & $5.72^{\mathrm{fg}}$ & $6.66^{\mathrm{bc}}$ & $7.38 \mathrm{~b}^{\mathrm{cd}}$ & $5.14^{\mathrm{e}}$ & $6.21^{\mathrm{g}}$ \\
G2 & $6.45^{\mathrm{ef}}$ & $5.74^{\mathrm{hi}}$ & $6.66^{\mathrm{de}}$ & $4.33^{\mathrm{i}}$ & $6.07^{\mathrm{d}}$ & $5.99^{\mathrm{e}}$ & $5.59^{\mathrm{d}}$ & $5.83^{\mathrm{h}}$ \\
G3 & $6.76^{\mathrm{d}}$ & $5.98^{\mathrm{gh}}$ & $7.25^{\mathrm{c}}$ & $5.42^{\mathrm{h}}$ & $5.79^{\mathrm{e}}$ & $7.40 \mathrm{~b}^{\mathrm{cd}}$ & $5.85^{\mathrm{bcd}}$ & $6.35^{\mathrm{ef}}$ \\
G5 & $6.73^{\mathrm{d}}$ & $6.86^{\mathrm{bc}}$ & $6.88^{\mathrm{d}}$ & $5.98^{\mathrm{ef}}$ & $6.10^{\mathrm{d}}$ & $7.54^{\mathrm{b}}$ & $5.90^{\mathrm{bc}}$ & $6.57^{\mathrm{c}}$ \\
G6 & $6.23^{\mathrm{fg}}$ & $6.04^{\mathrm{fg}}$ & $7.59^{\mathrm{ab}}$ & $5.51^{\mathrm{gh}}$ & $7.38^{\mathrm{a}}$ & $7.12^{\mathrm{d}}$ & $5.81^{\mathrm{bcd}}$ & $6.52^{\mathrm{cd}}$ \\
G7 & $7.46^{\mathrm{c}}$ & $6.10^{\mathrm{fg}}$ & $7.35^{\mathrm{bc}}$ & $7.75^{\mathrm{a}}$ & $6.80^{\mathrm{b}}$ & $7.18^{\mathrm{cd}}$ & $5.84^{\mathrm{bcd}}$ & $6.92^{\mathrm{b}}$ \\
G8 & $7.29^{\mathrm{c}}$ & $6.18^{\mathrm{fg}}$ & $7.28^{\mathrm{c}}$ & $4.38^{\mathrm{i}}$ & $6.40^{\mathrm{c}}$ & $6.04^{\mathrm{e}}$ & $5.19^{\mathrm{e}}$ & $6.11^{\mathrm{g}}$ \\
G9 & $6.31^{\mathrm{f}}$ & $6.31^{\mathrm{ef}}$ & $6.64^{\mathrm{de}}$ & $6.11^{\mathrm{e}}$ & $5.60^{\mathrm{ef}}$ & $7.21^{\mathrm{cd}}$ & $5.05^{\mathrm{ef}}$ & $6.17^{\mathrm{g}}$ \\
G10 & $8.76^{\mathrm{a}}$ & $7.38^{\mathrm{a}}$ & $7.74^{\mathrm{a}}$ & $7.21^{\mathrm{b}}$ & $6.80^{\mathrm{b}}$ & $7.10^{\mathrm{d}}$ & $6.07^{\mathrm{ab}}$ & $7.29^{\mathrm{a}}$ \\
G12 & $6.90^{\mathrm{d}}$ & $5.75^{\mathrm{hi}}$ & $6.50^{\mathrm{e}}$ & $7.22^{\mathrm{b}}$ & $6.54^{\mathrm{bc}}$ & $6.58^{\mathrm{e}}$ & $5.60^{\mathrm{d}}$ & $6.44^{\mathrm{de}}$ \\
G13 & $6.64^{\mathrm{de}}$ & $6.63^{\mathrm{cd}}$ & $7.18^{\mathrm{c}}$ & $6.75^{\mathrm{cd}}$ & $5.45^{\mathrm{f}}$ & $6.58^{\mathrm{e}}$ & $5.12^{\mathrm{d}}$ & $6.33^{\mathrm{f}}$ \\
G14 & $6.03^{\mathrm{g}}$ & $6.49^{\mathrm{de}}$ & $7.80^{\mathrm{a}}$ & $6.66^{\mathrm{d}}$ & $6.40^{\mathrm{c}}$ & $6.66^{\mathrm{e}}$ & $6.32^{\mathrm{e}}$ & $6.62^{\mathrm{c}}$ \\
G15 & $8.50^{\mathrm{b}}$ & $6.99^{\mathrm{b}}$ & $6.54^{\mathrm{e}}$ & $6.14^{\mathrm{e}}$ & $6.84^{\mathrm{b}}$ & $7.43^{\mathrm{bc}}$ & $5.78^{\mathrm{cd}}$ & $6.89^{\mathrm{b}}$ \\
Mean & $6.33^{\mathrm{f}}$ & $7.05^{\mathrm{b}}$ & $6.07^{\mathrm{f}}$ & $6.98^{\mathrm{bc}}$ & $6.78^{\mathrm{b}}$ & $6.19^{\mathrm{e}}$ & $4.78^{\mathrm{ef}}$ & $6.31^{\mathrm{f}}$ \\
\hline
\end{tabular}

Different letters within the same column indicate significant differences between genotypes $(p \leq 0.05)$ 
genotypic response across environments. Therefore, GEI complicates the selection process as GEI reduces the usefulness of genotypes by confounding their yield performance and minimizing the association between genotypic and phenotypic values (Crossa 1990).

The GE interaction sum of squares is further portioned into six significant Interaction Principal Components Axes (IPCAs). The six interaction principal components (IPCA1, IPCA2, IPCA3, IPCA4, IPCA5 and IPCA6) explained 38.05\%, 22.43\%, $13.15 \%, 11.51 \%, 9.60 \%$ and $5.25 \%$ of the $\mathrm{G} \times \mathrm{E}$ interaction variation, respectively. However, for the confirmation of the variation revealed by $\mathrm{G} \times \mathrm{E}$, the first two multiplicative component axes were sufficient (Gauch 2006), which explained $60.48 \%$ of the total $\mathrm{G} \times \mathrm{E}$ variation among the barley mutant lines in this experiment. The results were in agreement with the previous research results which showed a similar magnitude of GEI variance revealed by the first two principal components of GEI (Mohammadi \& Nader Mahmoodi 2008; Kilic 2014; Pržulj et al. 2015).

In Figure 3, the IPCA1 scores for both the genotypes and environments were plotted against the grain yield for the genotypes and the environments.
In the biplot, the vertical line passing through the center of the biplot was the grand mean of the experiment $(6.50 \mathrm{t} / \mathrm{ha})$, and the horizontal line passed through at the IPCA1 axis score $=0$. The IPCA1 was highly significant and explained the interaction pattern better than other interaction axes. The mean of genotypes or environments in AMMI model 1 biplot located on the same parallel line, relative to the ordinate, have similar yield, while those located on the right side of the center of the axis having higher yields than those on the left side. In the biplot, six mutant lines (G4, G6, G9, G12, G15 and G13) and three environments (E1, E3 and E6) located at the right side of the grand mean were considered as high yielding genotypes and environments while their corresponding low yielding counterparts were located at the left side of the grand mean (Figure $3)$. The genotypes with IPCA1 scores close to zero, expressed general adaptation, whereas the larger scores depicted more specific adaptation to environments. Mutant lines (G1, G4, G8, G9, G12 and G13) had IPCA score value closer to zero, and were classified as stable, whereas the IPCA scores of genotypes (G2, G5, G6, G7, G10 and G14) were comparatively large, and this group of barley lines could be classified as unstable.

T a b 1 e 2

Combined AMMI analysis of variance for grain yield [t/ha] of barley genotypes in 7 growing seasons $(2010-2011-$ $2016-2017)$

\begin{tabular}{|c|c|c|c|c|c|c|}
\hline Source & $d f$ & SS & MS & $\begin{array}{l}\mathrm{SS} \\
{[\%]}\end{array}$ & $\begin{array}{c}\mathrm{G} \times \mathrm{E} \text { explained } \\
{[\%]}\end{array}$ & $\begin{array}{c}\text { Cumulative } \\
{[\%]}\end{array}$ \\
\hline Genotypes & 14 & 56.62 & $4.04^{+}$ & 20.54 & - & - \\
\hline Environments & 6 & 102.92 & $17.15^{+}$ & 37.34 & - & - \\
\hline Interactions & 84 & 116.11 & $1.38^{+}$ & 42.12 & - & - \\
\hline IPCA 1 & 19 & 44.18 & $2.33^{+}$ & - & 38.05 & 38.05 \\
\hline IPCA2 & 17 & 26.04 & $1.53^{+}$ & - & 22.43 & 60.48 \\
\hline IPCA3 & 15 & 15.27 & $1.02^{+}$ & - & 13.15 & 73.63 \\
\hline IPCA4 & 13 & 13.37 & $1.03^{+}$ & - & 11.51 & 85.14 \\
\hline IPCA5 & 11 & 11.15 & $1.01^{+}$ & - & 9.60 & 94.75 \\
\hline IPCA6 & 9 & 6.10 & $0.68^{+}$ & - & 5.25 & 100.00 \\
\hline Error & 315 & 10.65 & 0.03 & - & - & - \\
\hline
\end{tabular}

${ }^{+}$significance at $p<0.001$; SS - sums of squares; MS - means of squares; SS [\%] - total variation explained; IPCA interaction principal components axis 
AMMI stability value statistic (ASV) was developed by Purchase to quantify and rank the genotypes on the basis of their yield stability. Genotypes with least ASV scores are the most stable, on the other hand, genotypes with high ASV score are unstable (Purchase 2000). According to this model, G4, G1 and G8 were the most stable and G7, G15, G2 and G5 were the most unstable mutant lines (Table 3).

Stability per se should however not be the only parameter for selection, because the most stable genotypes would not necessarily give the best yield performance (Mohammadi et al. 2007). The YSI method incorporates both yield and stability into a single index, reducing the problem of using only yield stability as the single criteria for selection of genotypes. Yield Stability Index (YSI) discriminated G4, G9 and G16 with high adaptability and high grain yield for the conditions of Southeast Bulgaria (Table 3).

Ranking of genotypes relative to the ideal genotype is presented in Figure 4. In our study the partitioning of the GGE through GGE biplot analysis showed that PCA 1 and PCA 2 accounted for $43.20 \%$ and $19.84 \%$ of the GGE sum of squares for barley grain yield, explaining a total of $63.04 \%$ variation. An ideal genotype has the highest mean yield and is absolutely stable (that ranks the highest in all environments) (Yan \& Kang 2003). Such an ideal

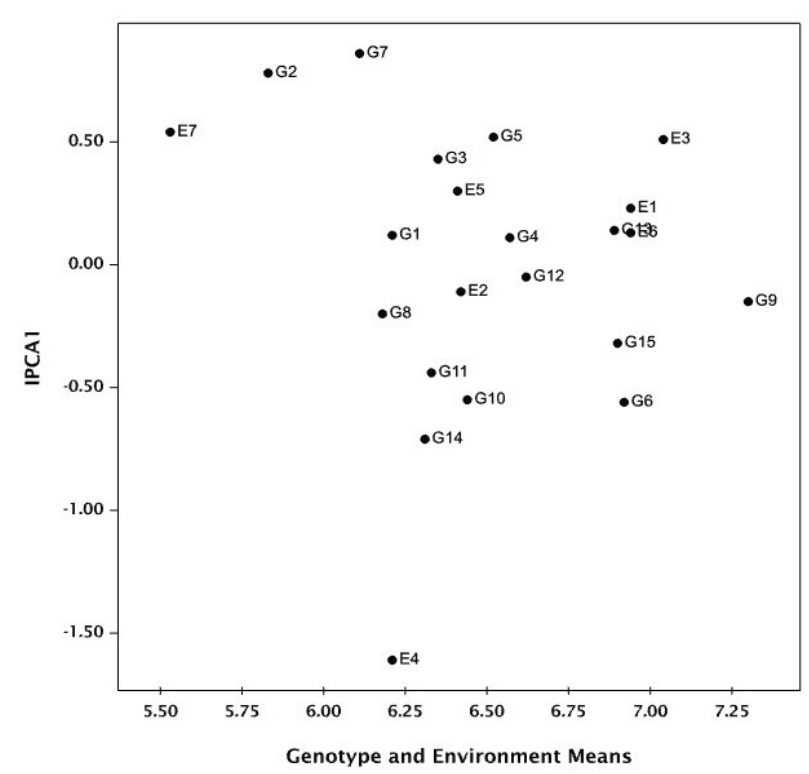

Figure 3. AMMI1 biplot for grain yield [t/ha] of of barley genotypes in 7 growing seasons (2010-2011-2016-2017) genotype is defined by having the greatest vector length of the high-yielding genotypes and with zero GE, as represented by the small circle with an arrow pointing to it (Yan 2001). A genotype is more desirable if it is closer to the ideal genotype. Although such as ideal genotype may not exist in reality, it can be used as a reference for genotype evaluation (Yan \& Tinker 2006). Therefore, genotypes G9 which fell into the center of concentric circles, was the ideal genotype in terms of higher yield ability and stability, compared with the rest of the genotypes. In addition, G15, G13 and G6 can be considered as desirable genotypes.

The results from this study indicate that GE interaction is a significant source of variation for grain yield of winter barley mutant lines. This observed pattern of GE interaction for grain yield of barley suggests that genotypes respond differently in different environments, hence the need for biplot analysis, which allows visual interpretation of GE interaction and facilitates genotype recommendations. Subsequently, two types of biplots (AMMI1 and GGE) were used to graphically display, interpret and explore important sources of variation, namely genotype main effect and GE interaction, to identify the genotypes which were superior on their mean performance and stability. Both the GGE and AMMI1 biplots identified G9 as the highest yielding

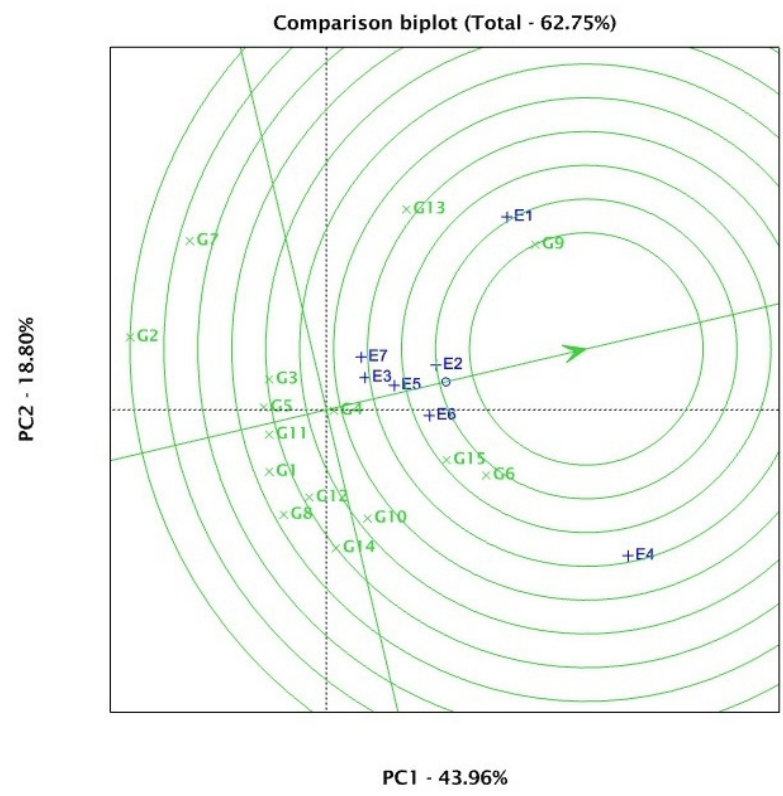

Figure 4. GGE biplot based on genotype-focused scaling for comparison of genotypes for their yield potential and stability 
$\mathrm{T}$ a $\mathrm{b} 1 \mathrm{e} \quad 3$

IPCA scores and stability parameters from AMMI model

\begin{tabular}{|l|c|r|r|r|r|r|r|c|}
\hline Genotype & Yield & Rank & IPCA1 & IPCA2 & ASV & Rank & YSI & Rank \\
\hline G1 & 6.21 & 12 & 0.12 & 0.20 & 0.282 & 2 & 14 & 3 \\
G2 & 5.83 & 15 & 0.78 & -0.02 & 1.323 & 14 & 29 & 9 \\
G3 & 6.35 & 9 & 0.43 & 0.20 & 0.759 & 7 & 16 & 5 \\
G4 & 6.57 & 6 & 0.11 & 0.11 & 0.221 & 1 & 7 & 1 \\
G5 & 6.52 & 7 & 0.52 & 0.61 & 1.079 & 12 & 19 & 7 \\
G6 & 6.92 & 2 & 0.56 & 0.07 & 0.948 & 11 & 13 & 2 \\
G7 & 6.11 & 14 & 0.86 & -0.42 & 1.519 & 15 & 29 & 9 \\
G8 & 6.17 & 13 & -0.20 & 0.14 & 0.361 & 3 & 16 & 5 \\
G9 & 7.29 & 1 & -0.15 & -0.70 & 0.750 & 6 & 7 & 1 \\
G10 & 6.44 & 8 & -0.55 & 0.05 & 0.929 & 10 & 18 & 6 \\
G11 & 6.33 & 10 & -0.44 & 0.03 & 0.742 & 5 & 15 & 4 \\
G12 & 6.62 & 5 & -0.05 & 0.77 & 0.776 & 8 & 13 & 2 \\
G13 & 6.89 & 4 & 0.14 & -0.88 & 0.912 & 9 & 13 & 2 \\
G14 & 6.31 & 11 & -0.71 & -0.11 & 1.203 & 13 & 24 & 8 \\
G15 & 6.90 & 3 & -0.32 & -0.06 & 0.553 & 4 & 7 & 1 \\
\hline
\end{tabular}

IPCA - interaction principal components axis; ASV - AMMI stability value; YSI - yield stability index

genotype with a low interaction with the environments and would, therefore, be suitable for cultivation in the region. Probably the higher yield stability of G9 was the result of the combination of better lodging tolerance and high tolerance to barley foliar diseases spread in the area. The mutant lines G6, G13, and G15 had a high mean grain yield and average GE interaction and could qualify for selection for a future hybridization program. In addition, G4 had adjudged the most stable genotype though high yielding by both biplots. The use of simultaneous selection for high yield and stability resulted in the selection of some genotypes with significant stability variance. These ordinarily, would have been discarded based on stability variance alone. The simultaneous selection for grain yield and yield stability is of the extreme importance in rain-fed conditions, where the environments are changeable and unpredictable (Vaezi et al. 2017). The large variation due to the environments in our study also confirmed the high diversity of weather conditions during growing seasons.

In our study both AMMI and GGE biplot demonstrate to be very useful in evaluating the per- formance of genotypes and showed no differences in selection of best genotypes. These results are in agreement with findings of Miranda et al. (2009), Mitrovic et al. (2012), Hagos and Abay (2013), Rad et al. (2013) and Jeberson et al. (2017).

\section{CONCLUSIONS}

The effect of genotype, environment and their interaction were highly significant for grain yield of mutant lines of 6-rowed winter barley tested during seven growing seasons in Southeast Bulgaria. The magnitude of genotype-by-environment interaction for grain yield was larger than that of genotype and environment main effects.

Both the AMMI and GGE biplot identified G9 as the highest yielding genotype with a low interaction with the environments, so this mutant line can be selected for further evaluation for variety release. The mutant lines G6, G13, and G15 were suggested for inclusion in the breeding program of winter barley due to its high grain yield and intermediate stability. 


\section{REFERENCES}

CROSSA, J. - GAUCH, H.G. - ZOBEL, R.W. 1990. Additive main effects and multiplicative interaction analysis of two international maize cultivar trials. In Crop Science, vol. 30, no. 3, pp. $493-500$.

FAO/IAEA MUTANT VARIETY DATABASE. 2019. FAO/ IAEA Mutant Variety Database. Available at https://mvd iaea.org/ (accessed January 10, 2019).

FARSHADFAR, E. 2008. Incorporation of AMMI stability value and grain yield in a single non-parametric index (GSI) in bread wheat. In Pakistan Journal of Biological Science, vol. 11, no. 14, pp. 1791-1796.

FRIEDT, W. 2011. Barley breeding history, progress, objectives, and technology. In ULLRICH, S.E. (Ed.) Barley: production, improvement, and uses. Wiley-Blackwel, pp. 160-186.

GABRIEL, K.R. 1971. The biplot graphic of matrices with application to principal component analysis. In Biometrics, vol. 58 , pp. $453-467$.

GAUCH, H.G. 1988. Model selection and validation for yield trials with interaction. In Biometrics, vol. 44, no. 3, pp. $705-715$.

GAUCH, H.G. 1992. Statistical analysis of regional yield trials: AMMI analysis of factorial designs. Amsterdam : Elsevier, $278 \mathrm{pp}$.

GAUCH, H.G. 2006. Statistical analysis of yield trials by AMMI and GGE. In Crop Science, vol. 46, pp. 1488-1500.

GAUCH, H.G. - ZOBEL, R.W. 1996. AMMI analysis of yield trials. In KANG, M. - GAUCH, H. (Eds.) Genotype by environment interaction. Boca Raton : CRC press, New York, pp. $85-122$.

GOCHEVA, M. 2014. Study of the productivity elements of spring barley using correlation and path-coefficients analysis. In Turkish Journal of Agricultural and Natural Sciences, vol. 2 , pp. $1638-1641$.

HAGOS, H.G. - ABAY, F. 2013. AMMI and GGE biplot analysis of bread wheat genotypes in the northern part of Ethiopia. In Journal of Plant Breeding and Genetics, vol. 1, no. 1, pp. $12-18$.

JEBERSON, M.S. - KANT, L. - KISHORE, N. - RANA, V. WALIA, D.P. - SINGH, D. 2017. AMMI and GGE biplot analysis of yield stability and adaptability of elite Genotypes of bread wheat (Triticum aestivum L.) for northern hill zone of India international. In Journal of Bio-resource and Stress Management, vol. 8, no. 5, pp. 635-641.

KILIC, H. 2014. Additive main effects and multiplicative interactions (AMMI) analysis of grain yield in barley genotypes across environments. In Tarım Bilimleri Dergisi, vol. 20, no. 4, pp. 337-344.

MIHOVA, G. 2013. Winter barley breeding at Dobrodzha Agricultural Institute - Genegal Toshevo. In Scietific works of the Institute of Agriculture - Karnobat, vol. 2, no. 1, pp. 23-38 (Bg).

MIRANDA, G.V. - SOUZA, L.V.D. - GUIMARÃES, L.J.M. - NAMORATO, H. - OLIVEIRA, L.R. - SOARES, M.O. 2009. Multivariate analyses of genotype $x$ environment interaction of popcorn. In Pesquisa Agropecuária Brasileira, vol. 44 , no. 1 , pp. $45-50$.

MITROVIC, B. - STANISAVLJEVI, D. - TRESKI, S. - STOJAKOVIC, M. - IVANOVIC, M. - BEKAVAC, G. - RAJKOVIC, M. 2012. Evaluation of experimental maize hybrids tested in multi-location trials using AMMI and GGE biplot analyses. In Turkish Journal of Field Crops, vol. 17, pp. $35-40$.

MOHAMMADI, R. - ABDULAHI, A. - HAGHPARAST, R. - ARMION, M. 2007. Interpreting genotype- environment interactions for durum wheat grain yields using non-parametric methods. In Euphytica, vol. 157, pp. 239-251.

MOHAMMADI, R. - NADER MAHMOODI, K. 2008. Stability analysis of grain yield in barley (Hordeum vulgare L.). In International Journal of Plant Breeding, vol. 2, no. 2, pp. $74-78$.

PRŽULJ, N. - MIROSAVLJEVIĆ, M. - ČANAK, P. - ZORIĆ, M. - BOĆANSKI, J. 2015. Evaluation of spring barley performance by biplot analysis. In Cereal research communications, vol. 43, no. 4, pp. 692-703.

PRŽULJ, N. - MOMČILOVIĆ, V. - SIMIĆ, J. - MIROSAVLJEVIĆ, M. 2014. Effect of growing season and variety on quality of spring two -rowed barley. In Genetika, vol. 46, pp. 59-73.

PURCHASE, J.L. - HATTING, H. - VAN DEVENTER, C.S. 2000. Genotype $\times$ environment interaction of winter wheat (Triticum aestivum L.) in South Africa: II. Stability analysis of yield performance. In South African Journal of Plant and Soil, vol. 17, pp. 101-107.

RAD, N.M. - KADIR, M.A. - RAFII, M.Y. - JAAFAR, H.Z. - NAGHAVI, M.R. - AHMADI, F. 2013. Genotype $\times$ environment interaction by AMMI and GGE biplot analysis in three consecutive generations of wheat (Triticum aestivum) under normal and drought stress conditions. In Australian Journal of Crop Science, vol. 7, pp. 956-961.

VAEZI, B. - POUR-ABOUGHADAREH, A. - MOHAMMADI, R. - ARMION, M. - MEHRABAN, A. - HOSSEIN-POUR, T. - DORII, M. 2017. GGE biplot and AMMI analysis of barley yield performance in Iran. In Cereal Research Communications, vol. 45 , no. 3 , pp. 500-511.

VALCHEVA, D. - VULCHEV, D. - POPOVA, T. - DIMOVA, D. - OZTURK, I. - KAYA, R. 2013. Productive abilities of Bulgarian and introduced varieties and lines barley in Southeast Bulgaria conditions. In Scientific works of the Institute of Agriculture - Karnobat, vol. 2, no. 1, pp. 39-48 (Bg).

VOLTAS, J. - VAN EEUWIJK, F.A. - IGARTUA, E. GARCIA DEL MORAL, L.F. - MOLINA-CANO, J.L. - ROMAGOSA, I. 2002. Genotype by environment interaction and adaptation in barley breeding: basic concepts and methods of analysis. In SLAFER, G.A. - MOLINACANO, J.L. - SAVIN, R. - ARAUS, J.L. - ROMAGOSA, I. (Eds.) Barley science: recent advances from molecular biology to agronomy of yield and quality. New York, Food Product Press, pp. 205-241. ISBN 1-56022-909-8.

YAN, W. 2001. GGE biplot - a windows application for graphical analysis of multi-environment trial data and other types of two way data. In Agronomy Journal, vol. 93, pp. $1111-1118$.

YAN, W. - HUNT, L.A. - SHENG, Q. - SZLAVNICS, Z. 2000. Cultivar evaluation and mega environment investigation based on the GGE biplot. In Crop Science, vol. 40, pp. 597-605.

YAN, W. - KANG, M. S. 2003. GGE biplot analysis: a graphical tool for breeders. In KANG M.S. (Ed.) Geneticists, and Agronomist. CRC Press, Boca Raton, FL. pp. 63-88.

YAN, W. - RAJCAN, I. 2002. Biplot analysis of test sites and trait relations of soybean in Ontario. In Crop Science, vol. 42 , pp. $11-20$

YAN, W. - TINKER, N. A. 2006. Biplot analysis of multienvironment trial data: principles and applications. In Canadian Journal of Plant Science, vol. 86, pp. 623-645.

ZOBEL, R.W. - WRIGHT, M.J. - GAUCH, H.G. 1988. Statistical analysis of a yield trial. In Agronomy Journal, vol. 80, pp. 388-393.

Received: February 28, 2019 Accepted: June 6, 2019 